\title{
Oxidative Stress Regulated Iron Regulatory Protein IRP2 Through FBXL5-Mediated Ubiquitination-Proteasome Way in SH-SY5Y Cells
}

\author{
Qian Jiao, Xixun Du, Jie Wei, Yong Li and Hong Jiang*
}

Department of Physiology, Shandong Provincial Key Laboratory of Pathogenesis and Prevention of Neurological Disorders and State Key Disciplines: Physiology, School of Basic Medicine, Qingdao University, Qingdao, China

\section{OPEN ACCESS}

Edited by:

Massimiliano Filosto, Asst degli Spedali Civili di Brescia,

Italy

Reviewed by:

Philipp Janker Kahle,

Hertie-Institut für klinische Hirnforschung (HIH), Germany

Xuping Li,

Houston Methodist Research Institute, United States

*Correspondence: Hong Jiang

hongjiang@qdu.edu.cn

Specialty section: This article was submitted to

Neurodegeneration,

a section of the journal

Frontiers in Neuroscience

Received: 21 May 2018 Accepted: 10 January 2019 Published: 29 January 2019

Citation:

Jiao Q, Du X, Wei J, Li Y and Jiang $H$ (2019) Oxidative Stress

Regulated Iron Regulatory Protein IRP2 Through FBXL5-Mediated Ubiquitination-Proteasome Way in SH-SY5Y Cells.

Front. Neurosci. 13:20. doi: 10.3389/fnins.2019.00020
Iron regulatory protein 2 (IRP2) plays a key role in the cellular iron homeostasis and could be regulated by a variety of factors, such as oxidative stress, hypoxia and iron, etc. IRP2 depletion results in neurodegenerative movement disorder with the loss of neurons and accumulations of iron. Since oxidative stress extensively exists in several neurodegenerative diseases where iron accumulation also exists, it is important to clarify the mechanisms underlying the effects of oxidative stress on IRP2 expression and its consequence. 200 and $300 \mu \mathrm{M} \mathrm{H}_{2} \mathrm{O}_{2}$ could result in the reduced cell viability in $\mathrm{SH}$ SY5Y cells. The intracellular levels of reactive oxygen species (ROS) were increased by 52.2 and $87.3 \%$ with 200 and $300 \mu \mathrm{M} \mathrm{H}_{2} \mathrm{O}_{2}$ treatments, respectively. The decreased levels of mitochondrial transmembrane potential $(\Delta \Psi \mathrm{m})$ were only observed in $300 \mu \mathrm{M}$ $\mathrm{H}_{2} \mathrm{O}_{2}$-treated group. The protein levels of IRP2, but not for its mRNA levels, were observed decreased in both groups, which resulted in the lower TfR1 expression and decreased iron uptake in these cells. Pretreatment with MG132, the decreased IRP2 levels caused by $\mathrm{H}_{2} \mathrm{O}_{2}$ treatment could be antagonized. The protein levels of $\mathrm{F}$ box and leucine-rich repeat protein 5 (FBXL5), the only E3 ligase of IRP2, were observed decreased accordingly. When knockdown the intracellular FBXL5 levels by si-FBXL5, the protein levels of IRP2 were found increased with $\mathrm{H}_{2} \mathrm{O}_{2}$ treatment. Our results suggest that FBXL5 is involved in the degradation of IRP2 under oxidative stress in dopaminergic-like neuroblastoma cells, which implies that its role in the neuronal regulation of IRP2 in neurodegenerative diseases.

Keywords: oxidative stress, IRP2, FBXL5, iron metabolism, ubiquitination

\section{INTRODUCTION}

Oxidative stress occurs when the accumulated production of reactive oxygen species (ROS) and the decrease of antioxidant activity. It is thought to be one of common underlying mechanisms that lead to cellular dysfunction in neurodegenerative disease (Pong, 2003; Dias et al., 2013). As such, the substantia nigra (SN) exhibits increased levels of oxidized lipids, damaged proteins, and DNA in Parkinson's disease (PD) (Hwang, 2013). Moreover, iron levels in the SN have been reported to be elevated in patients with PD (Sofic et al., 1988; Dexter et al., 1989) and PD animal models (Wang et al., 2004; Jiang et al., 2010; You et al., 2015). Markers of oxidative stress also increase in both Alzheimer's disease (AD) patients models brain 
areas in which amyloid $\beta(\mathrm{A} \beta)$ is abundant (Butterfield et al., 2001). A $\beta$ plaques can efficiently generate ROS and accelerate iron accumulation (Smith et al., 2007; van Duijn et al., 2017). Thus, the oxidative stress may play an important role in inducing iron metabolic disorder in neurodegeneration associated with several brain pathologies.

Iron homeostasis is regulated by coordination proteins that are responsible for iron uptake, storage, exports, and utilization in the cellular (Hentze et al., 2010). Iron regulatory protein(IRPs), including IRP1 and IRP2, are RNA-binding proteins that interact with RNA stem loops known as iron responsive element (IRE) to regulate the translation and stability of mRNAs that encode proteins required for iron homeostasis, including ferritin, ferroportin (Fpn), transferrin receptor (TfR) and divalent metal transporter 1 (DMT1) (Rouault, 2006; Muckenthaler et al., 2008). It has been reported that a syndrome of progressive neurodegenerative disease and anemia develops with iron deposits in white matter and a loss of Purkinje cells in IRP2 ${ }^{-/-}$mice, whereas IRP1 $1^{-/-}$mice develop polycythemia and pulmonary hypertension, indicating a prominent role of IRP2 in controlling neuronal iron metabolism (Meyron-Holtz et al., 2004; Wilkinson and Pantopoulos, 2014). But some studies considered that IRP2 deficiency without symptomatic neurodegeneration in the mouse (Galy et al., 2006). Our previous study showed that IRP2 expression is decreased in 1-Methyl4-phenylpyridinium $[\mathrm{MPP}(+)]$-induced cellular model of PD (Zhang et al., 2009), whereas IRP2 expression is increased in 6-hydroxydopamine (6- OHDA)-treated PD model (Jiang et al., 2010). In AD patients, IRP2 immunoreactivity is present in the intracellular neurofibrillary, including neurofibrillary tangles and neuropil threads, which is striking differences from the control brain (Smith et al., 1998). These suggest that IRP2 expression disruption exists in neurodegenerative diseases where oxidative stress extensively occurs. In peripheral system, such as liver and kidney, IRP2 is rapidly degraded through ubiquitin-proteasomal system in high iron and high oxygen pressure conditions (Kuhn, 2015). Additionally, hypoxia and low iron level can prevent IRP2 degradation. However, in nerve system, the underlying mechanisms of oxidative stress regulate IRP2 expression and the homeostasis of iron is not fully understood.

Iron regulatory protein 2 has unique 73 -amino acid that is different from IRP1 (Iwai et al., 1995). Deletion of this sequence eliminates the rapid turnover of IRP2, and does not show a sensitivity to F box and leucine-rich repeat protein 5 (FBXL5) (Iwai et al., 1995; Salahudeen et al., 2009). FBXL5, an iron- and oxygen-regulated SCF-type ubiquitin ligase (E3), has been shown to contribute to iron-dependent degradation of IRP2 in liver or human embryonic kidney cells (Salahudeen et al., 2009; Vashisht et al., 2009; Moroishi et al., 2011). Here, we used SH-SY5Y cells, a dopaminergic-like neuroblastoma cell, to investigate the regulation mechanism of IRP2 under oxidative stress condition in nerve system. We found that oxidative stress induced by $\mathrm{H}_{2} \mathrm{O}_{2}$ reduced IRP2 protein levels through ubiquitination-proteasome way. Our results also revealed that E3 FBXL5 plays a pivotal role in the regulation of IRP2 protein levels under oxidative stress condition in nerve system.

\section{MATERIALS AND METHODS}

\section{Cell Culture and Treatment}

The SH-SY5Y cell line was purchased from the Cell Bank of the Shanghai Institute of Cell Biology and Biochemistry, Chinese Academy of Sciences (Shanghai, China). SH-SY5Y cells were cultured in DMEM/F12 (Dulbecco's modified Eagle medium and Ham's F12, 1:1, pH 7.4) with 10\% fetal bovine serum (FBS), $100 \mathrm{U} / \mathrm{mL}$ of penicillin and $100 \mathrm{U} / \mathrm{mL}$ of streptomycin (all from Invitrogen, United States) at $37^{\circ} \mathrm{C}$ in a humidified atmosphere containing $5 \% \mathrm{CO}_{2}$. For experiments, cells were seeded in 6 well plates with $1 \times 10^{5}$ cells $/ \mathrm{mL}$ and grown to $80-90 \%$ confluency before they were treated with $\mathrm{H}_{2} \mathrm{O}_{2}(20,30,50,200,300,500$, and $1000 \mu \mathrm{mol} / \mathrm{L}$ ) for $24 \mathrm{~h}$. After $24 \mathrm{~h}$, the medium was replaced with medium containing $\mathrm{H}_{2} \mathrm{O}_{2}$, and cells were treated for another $24 \mathrm{~h}$ and then harvested for experiments.

\section{Transfection of shRNA}

The FBXL5 short hairpin RNA (shRNA) and the scramble shRNA control were pre-designed and purchased from Genechem

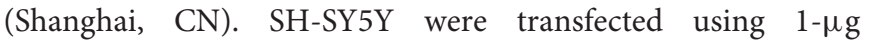
plasmid and $2.5-\mu \mathrm{L}$ Lipofectamine 2000 reagent (Invitrogen, United States) in $800-\mu \mathrm{L}$ transfection medium per well in 12 well plate for $24 \mathrm{~h}$ optimal transfection and then used for the following experiments.

\section{Cell Viability}

The cell viability was detected by the conventional 3-(4,5dimethylthiazol-2-yl) -2, 5-diphenyltetrazolium bromide (MTT) (Beyotime, CN) assay. The MTT assay is a colorimetric assay for measuring the activity of cellular enzymes that reduce the tetrazolium dye. Cells were incubated in MTT $(5 \mathrm{mg} / \mathrm{mL})$ for 3-4 h. $100 \mu \mathrm{L}$ DMSO was added to each well after medium was removed. The formazan dye crystals were solubilized for $10 \mathrm{~min}$, and absorbance was measured at 494 and $630 \mathrm{~nm}$ with a spectrophotometer (Molecular Device, M5, United States).

\section{Measurement of the Mitochondrial Transmembrane Potential $(\Delta \Psi \mathrm{m})$ and the Production of Intracellular Reactive Oxygen Species (ROS)}

Changes in the levels of intracellular ROS and $\Delta \Psi \mathrm{m}$ with $\mathrm{H}_{2} \mathrm{O}_{2}$ (200 and $300 \mu \mathrm{mol} / \mathrm{L}$ ) treatment of SH-SY5Y were measured using flow cytometry with Rhodamine 123 (Sigma, United States) or carboxy-H2DCFDA dye (Invitrogen, United Kingdom) as previously described (Jiang et al., 2010). After cells were washed with HEPES buffered saline (HBS, $10 \mathrm{mM}$ of HEPES, $150 \mathrm{mM}$ of $\mathrm{NaCl}, \mathrm{pH} 7.4)$ three times, carboxy-H2DCFDA $(5 \mu \mathrm{M})$ was added and incubated for $30 \mathrm{~min}$ at $37^{\circ} \mathrm{C}$. Cells were washed with HBS two times, followed by centrifugation at $800 \mathrm{rpm}$ for $5 \mathrm{~min}$, and re-suspended in $1 \mathrm{~mL}$ HBS. Intracellular ROS generation was also assayed by Rhodamine $123(5 \mu \mathrm{g} / \mathrm{mL})$. Fluorescent intensity was recorded at $488 \mathrm{~nm}$ excitation and $525 \mathrm{~nm}$ emission wavelengths (Fluorescence 1, FL1). Results were demonstrated as FL1-H (Fluorescence 1-Histogram), setting the gated region M1 
and $\mathrm{M} 2$ as a marker to observe the changing levels of fluorescence intensity using Cellquest Software.

\section{Calcein Loading of Cells and Ferrous Iron Influx Assay}

Ferrous iron influx were detected as previously described (Zhang et al., 2009; Du et al., 2016). Calcein-AM (Molecular Probes, United States) is a membrane-permeative, and forms fluorescent calcein by cytoplasmic esterases upon intracellular cleavage. This reaction is $\mathrm{pH}$ independent and can be quenched rapidly by divalent metals and reversed easily by chelators. The cells were planted in glass coverslips and incubated with calcein-AM $(0.5 \mu \mathrm{M})$ in $\mathrm{HBS}$ at $37^{\circ} \mathrm{C}$ for $30 \mathrm{~min}$. The excess calcein on the cell surface was washed for three times with HBS. Calcein fluorescence was recorded at an excitation wavelength of $488 \mathrm{~nm}$ and an emission wavelength of $525 \mathrm{~nm}$ and the fluorescence intensity was measured every $3 \mathrm{~min}$ for $30 \mathrm{~min}$ with continuous perfusion of $100 \mu \mathrm{M}$ of ferrous iron (ferrous sulfate in an ascorbic acid solution, 1:44 molar ratio; prepared immediately before the experiments). Ascorbic acid maintained the reduced status of ferrous iron, in addition, ascorbate acted as a chelator to maintain the iron in solution. The mean fluorescence signal of 25-30 single cells in four separate fields was monitored at $200 \times$ magnification and processed with Fluoview 5.0 software.

\section{Quantitative Real-Time PCR}

SH-SY5Y cells were collected for the investigation of FBXL5 and IRP2 mRNA expression by quantitative real-time PCR (qRT-PCR). Total RNA was extracted by using the Trizol reagent (Invitrogen) in accordance with manufacturer's protocol and was quantified by spectrophotometry (Bio-Rad, United States). RNAs were reversely transcribed to cDNA by a reverse transcriptase kit (RevertAid First Strand Cdna Synthesis Kit, Thermo, United States). Relative abundance of each mRNA was quantified by qRT-PCR using specific primers and the SYBR Premix Ex TaqII (TaKaRa, CN). Primers for rat FBXL5 (forward 5' - TTAACTAACAAGGGCATTGGAGAAG $-3^{\prime}$; reverse $5^{\prime}$ - TCAGCCAAATCTTCAGCATCTAAC $\left.-3^{\prime}\right)$, IRP2 (forward 5'-CGCCTTTGAGTACCTTATTGAAACA$3^{\prime}$; reverse $5^{\prime}$-CGTACAGCAGCTTCCA ACAAGA-3') and GAPDH (forward 5'-GCACCGTCAAGGCTGAGAAC-3'; reverse $5^{\prime}$-TGGTGAAGACGCCAGTGGA-3') were synthesized by TaKaRa. QRT-PCR reactions were carried out by using Real-Time PCR Detection System (Eppendorf,GER). Data were analyzed by the $2^{\Delta \Delta} \mathrm{CT}$ method, and GAPDH was taken as an internal control.

\section{Western Blot Analysis}

The SH-SY5Y cells were washed with ice-cold PBS and lysed in lysis buffer (Cwbio, CN) containing protease inhibitors cocktail (Rhoche, GER) for $30 \mathrm{~min}$. The lysates were centrifuged at $12,000 \times \mathrm{g}$ for $10 \mathrm{~min}$, and the protein concentration of the supernatants was determined with a Pierce ${ }^{\mathrm{TM}} \mathrm{BCA}$ Protein Assay Kit (Thermo, United States). A total of $20 \mu \mathrm{g}$ of protein was electrophoresed on $8 \%$ SDS polyacrylamide gels and transferred onto PVDF membranes (300 mA, $90 \mathrm{~min}$ ). After blocking with $10 \%$ non-fat milk for $1 \mathrm{~h}$ at room temperature, the membranes were incubated overnight at $4^{\circ} \mathrm{C}$ with rabbit antiFBXL5 (1:1000, Abcam, United Kingdom), rabbit anti-IRP2 (1:1000, Abcam, United Kingdom), rabbit anti-TfR1 (1:1000, Abcam, United Kingdom ) and rabbit anti- $\beta$-actin monoclonal antibody (1:10000, BIOS, CN). The cross-reactivity was visualized using ECL Kit (Millopore, United States) and analyzed through scanning densitometry with a UVP image system.

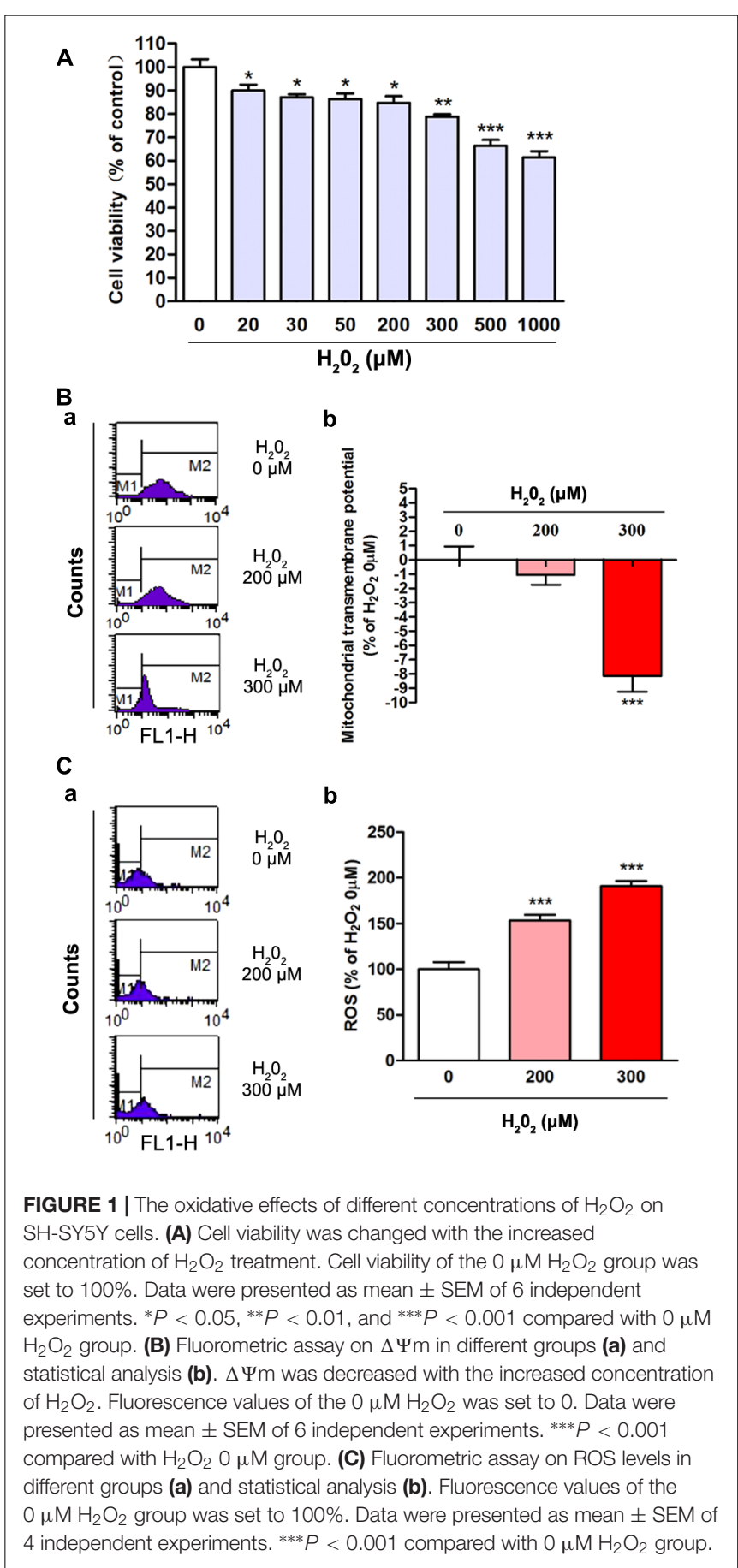


A

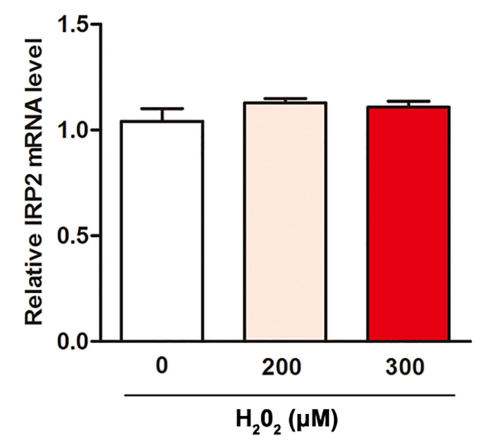

C

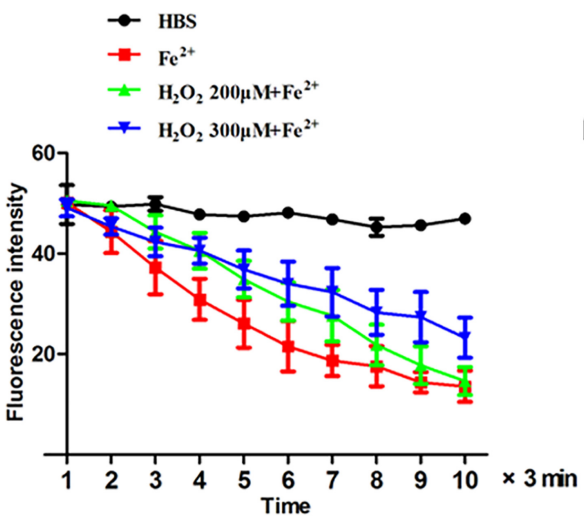

B
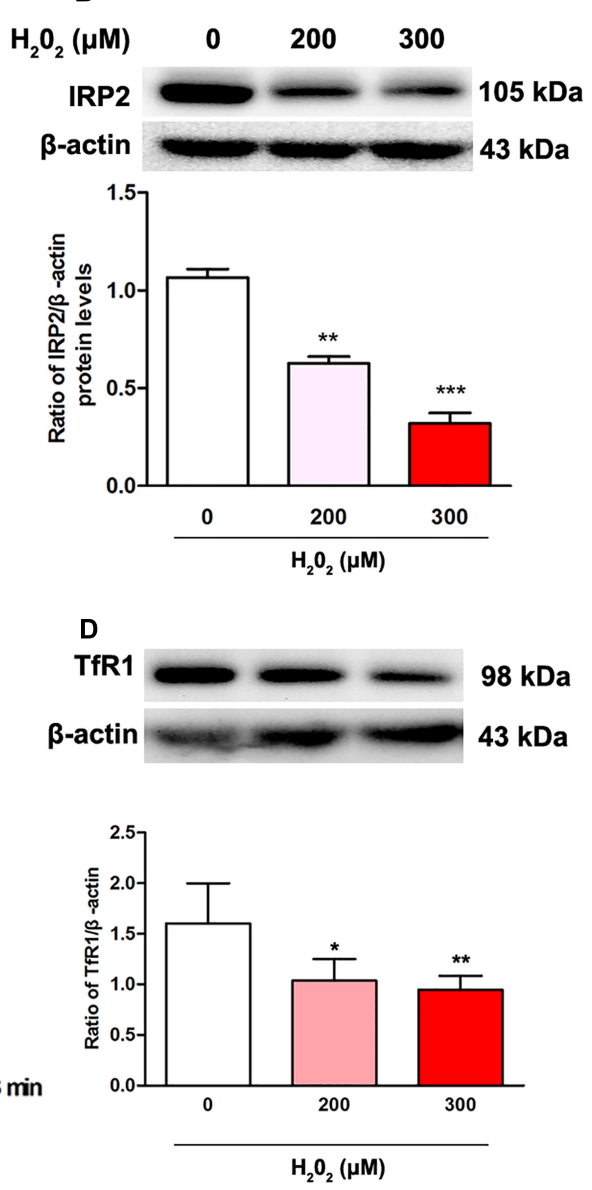

FIGURE $2 \mid \mathrm{H}_{2} \mathrm{O}_{2}$ induced the changes in IRP2 levels and ferrous iron uptake in SH-SY5Y cells. (A) IRP2 mRNA levels were changed with $\mathrm{H}_{2} \mathrm{O}_{2}$ treatment. One-way ANOVA, data were presented as mean \pm SEM of 3 independent experiments. (B) IRP2 protein levels were changed with $\mathrm{H}_{2} \mathrm{O}_{2}$ treatment. One-way ANOVA, data were presented as mean \pm SEM of 3 independent experiments. ${ }^{*} P<0.05,{ }^{*} P<0.01$, and ${ }^{* * *} P<0.001$ compared with $\mathrm{H}_{2} \mathrm{O}_{2} 0 \mu \mathrm{M}$ group. (C) Calcein-indicated ferrous iron ( $\mathrm{FeSO}_{4}$ ) influx in $\mathrm{SH}-\mathrm{SY} 5 \mathrm{Y}$ cells. The fluorescence intensity of SH-SY5Y cells in $200 \mu \mathrm{M}$ group and $300 \mu \mathrm{M}$ group were significantly higher than that in $0 \mu \mathrm{M} \mathrm{H}_{2} \mathrm{O}_{2}$ group. Two-way ANOVA, ${ }^{*} P<0.05$. The mean fluorescence intensity of 35 separate cells from 4 separate fields at each time point was presented as mean \pm SEM of 6 independent experiments. (D) TfR1 protein levels were changed with $\mathrm{H}_{2} \mathrm{O}_{2}$ treatment. One-way ANOVA, data were presented as mean \pm SEM of 3 independent experiments. ${ }^{*} P<0.05$ and ${ }^{* *} P<0.01$ compared with $\mathrm{H}_{2} \mathrm{O}_{2} \mathrm{O} \mu \mathrm{M}$ group.

\section{Statistical Analysis}

Results are presented as means \pm SEM. One-way analysis of variance (ANOVA) followed by the Tukey's Multiple Comparison Test was used to compare difference between means in more than two groups. The iron uptake experiment was carried out using two-way ANOVA followed by the Student-Newman-Keuls test. A probability of $P<0.05$ was taken to indicate statistical significance.

\section{RESULTS}

\section{The Oxidative Effects of $\mathrm{H}_{2} \mathrm{O}_{2}$ on SH-SY5Y Cells}

To elucidate the oxidative effects of $\mathrm{H}_{2} \mathrm{O}_{2}$, we assessed cell viability, $\Delta \Psi \mathrm{m}$ and ROS in the present study. SH-SY5Y cells were treated with different concentrations of $\mathrm{H}_{2} \mathrm{O}_{2}$ for $24 \mathrm{~h}$ and then MTT method was used to detect the cell viability. The results showed that the cell viability was decreased with the increased concentration of $\mathrm{H}_{2} \mathrm{O}_{2}$ (Figure 1A). In comparing with the $0 \mu \mathrm{M} \mathrm{H} \mathrm{H}_{2} \mathrm{O}_{2}$ group, the cell viability in $20,30,50,200,300,500$ and $1000 \mu \mathrm{M} \mathrm{H} \mathrm{H}_{2} \mathrm{O}_{2}$ group was decreased by $10.2,12.9,13.7,15.3,21.2,33.6$, and $38.6 \%$, respectively, which displayed significant differences (Figure 1A, $P<0.05)$. The 200 and $300 \mu \mathrm{M}$ effective concentration of $\mathrm{H}_{2} \mathrm{O}_{2}$ were applied for the following studies. Oxidative stress induced $\Delta \Psi \mathrm{m}$ reduction and excessive generation of ROS which contribute to DNA or RNA damage. We found that the $\Delta \Psi \mathrm{m}$ in cells was decreased significantly in $300 \mu \mathrm{M} \mathrm{H}_{2} \mathrm{O}_{2}$ treatment group (Figure 1B, $P<0.001$ ). The intracellular ROS levels were increased by 52.2 and $87.3 \%$, respectively, and the difference was statistically significant $(P<0.001)$ when compared with the $0 \mu \mathrm{M} \mathrm{H}_{2} \mathrm{O}_{2}$ group 
(Figure 1C). Thus, these observations indicated that appropriate concentrations of $\mathrm{H}_{2} \mathrm{O}_{2}$ could induce oxidative stress in $\mathrm{SH}$ SY5Y cells.

\section{$\mathrm{H}_{2} \mathrm{O}_{2}$ Induced a Reduction in IRP2 Expression and Ferrous Iron Uptake}

To test the relationship of IRP2 expression and oxidative stress induced by $\mathrm{H}_{2} \mathrm{O}_{2}$, we examined the expression of IRP2 in mRNA and protein levels. After SH-SY5Y cells were treated with $200 \mu \mathrm{M}$ or $300 \mu \mathrm{M}$ of $\mathrm{H}_{2} \mathrm{O}_{2}$ for $24 \mathrm{~h}$, the mRNA levels of IRP2 showed that no significant difference (Figure 2A, $P>0.05$ ), whereas the protein levels of IRP2 were decreased in comparison with the $0 \mu \mathrm{M} \mathrm{H} \mathrm{H}_{2} \mathrm{O}_{2}$ group (Figure 2B, $P<0.01$ ). Thus, $\mathrm{H}_{2} \mathrm{O}_{2}$ regulated IRP2 expression in protein levels. The $\mathrm{SH}$ SY5Y cells were incubated with $100 \mu \mathrm{M} \mathrm{Fe}{ }^{2+}$ to detect the ability of cell iron uptake. Cell iron uptake ability was observed using laser confocal microscopy, and the results showed that the intracellular fluorescence intensity was increased with time, indicating a decreased $\mathrm{Fe}^{2+}$ uptake in both $200 \mu \mathrm{M}$ and $300 \mu \mathrm{M}$ $\mathrm{H}_{2} \mathrm{O}_{2}$ treatment groups (Figure 2C, $P<0.05$ ). Moreover, the expression of TfRlin 200 and $300 \mu \mathrm{M} \mathrm{H} \mathrm{H}_{2} \mathrm{O}_{2}$ treatment groups were also decreased (Figure 2D, $P<0.05$ ). These results suggested that $\mathrm{H}_{2} \mathrm{O}_{2}$ treatment resulted in a decrease of IRP2 protein levels rather than mRNA levels, leading to downregulation of IRP2 targets and iron uptake ability.

\section{The Down-Regulative Effects of $\mathrm{H}_{2} \mathrm{O}_{2}$ on IRP2 Protein Levels Through Ubiquitination Pathway}

We next examined how such $\mathrm{H}_{2} \mathrm{O}_{2}$ affected IRP2 protein levels. To determine the expression of IRP2 that induced by $\mathrm{H}_{2} \mathrm{O}_{2}$ through ubiquitination pathway, we incubated SH-SY5Y cells with the ubiquitin proteasome inhibitor MG132. Figure 3 showed that the expression levels of IRP2 levels were decreased in $\mathrm{H}_{2} \mathrm{O}_{2}$ treatment groups and were restored by MG132 treatment, the difference was statistically significant $(P<0.05)$.

\section{FBXL5 Was Involved in the Degradation of IRP2 Induced by $\mathrm{H}_{2} \mathrm{O}_{2}$}

$\mathrm{F}$ box and leucine-rich repeat protein 5, an E3 ubiquitin ligase subunit, is a key event to mediate IRP2 degradation for controlling iron homeostasis (Moroishi et al., 2011). To test our hypothesis that IRP2 reduction was raised by FBXL5 in the oxidative environment, we measured the FBXL5 expression both in mRNA and in protein levels. Results showed that the mRNA levels of FBXL5 showed no significant difference (Figure 4A, $P>0.05)$, whereas the protein levels of FBXL5 were increased in both $\mathrm{H}_{2} \mathrm{O}_{2}$ treatment groups (Figure 4B, $P<0.05$ ). These data indicated that oxidative factors $\mathrm{H}_{2} \mathrm{O}_{2}$ could cause the decrease of IRP2 and the increase of FBXL5.

Sh-FBXL5 were transfected into SH-SY5Y cells, and we found that FBXL5 levels were decreased in all $\mathrm{H}_{2} \mathrm{O}_{2}$ treatment groups (Figures 4Ca,b, $P<0.05$ ), and IRP2 levels were increased in all groups (Figures 4Ca,c, $P<0.05$ ), the difference was statistically significant in comparing with negative control. The

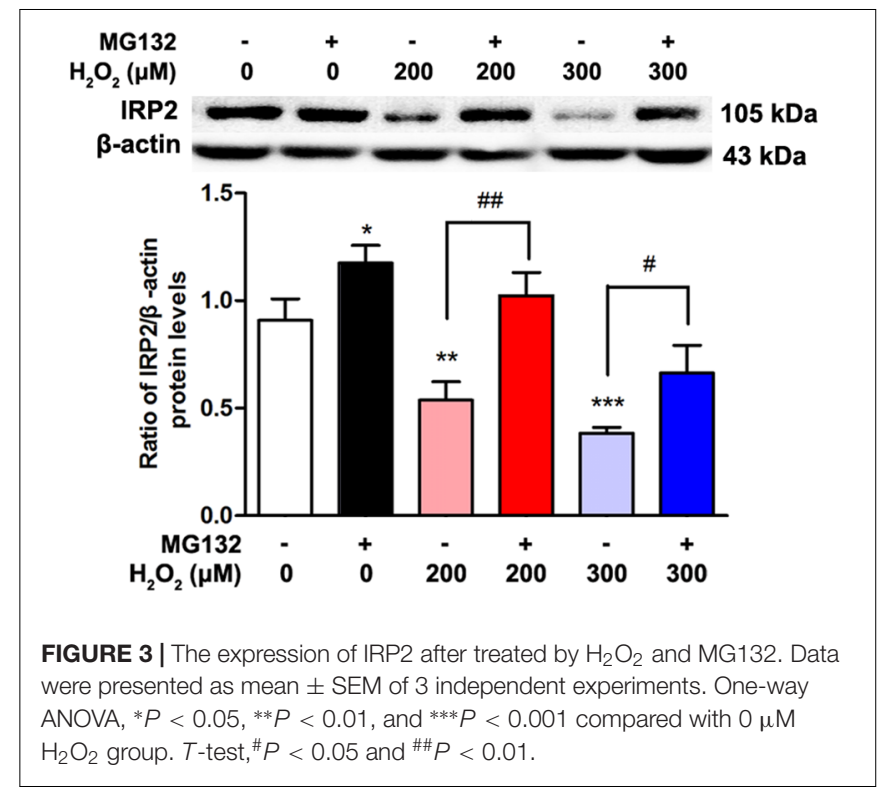

results suggested that $\mathrm{H}_{2} \mathrm{O}_{2}$ could down regulate IRP2 through FBXL5 mediated ubiquitination pathway.

\section{DISCUSSION}

We have shown that the oxidative stress induced by $\mathrm{H}_{2} \mathrm{O}_{2}$ in $\mathrm{SH}$ SY5Y cells resulted in a down-regulation of IRP2 protein levels, which in turn leads to a decrease of iron uptake ability. The IRP2 protein stability was regulated by ubiquitination pathway. FBXL5, the E3 of IRP2, was up-regulated after treatment of $\mathrm{H}_{2} \mathrm{O}_{2}$. The knockdown of FBXL5 could attenuate the IRP2 down-regulation that induced by $\mathrm{H}_{2} \mathrm{O}_{2}$. Our findings indicate that $\mathrm{H}_{2} \mathrm{O}_{2}$ regulated IRP2 expression through FBXL5 mediated ubiquitination pathway in SH-SY5Y cells.

Molecules or molecular fragments containing one or more unpaired electrons are called free radicals. These free radicals in living systems are mostly derived from oxygen (Jomova et al., 2010). The ROS, such as $\left(\mathrm{O}_{2}{ }^{-}\right)$, derived from metabolic processes, and then further interacts with other molecules via enzyme- or metal-catalyzed to generate "secondary" ROS (Jomova et al., 2010; Farina et al., 2013). Excessive exposure to ROS may induce oxidative stress particularly in mitochondria, and lead to neurodegenerative diseases. $\mathrm{H}_{2} \mathrm{O}_{2}$ generates oxygen by catalase, which lead to hyperoxia. And the free intracellular $\mathrm{Fe}^{2+}$ and $\mathrm{H}_{2} \mathrm{O}_{2}$ participate in the Fenton reaction to generate high reactive hydroxyl radical. Thus, in the present study, we used $\mathrm{H}_{2} \mathrm{O}_{2}$ mimic oxidative stress (Figure 1). The cell viability was reduced with the increased $\mathrm{H}_{2} \mathrm{O}_{2}$ concentrations (Figure 1A). The $\Delta \Psi \mathrm{m}$ reduction and excessive generation of ROS increased both in $\mathrm{H}_{2} \mathrm{O}_{2}$ (Figures $\mathbf{1 B}, \mathbf{C}$ ) treatment groups. These results indicated that cells were damaged by the artificial oxidative stress in vitro.

In the present study, we found that $\mathrm{H}_{2} \mathrm{O}_{2}$ reduced the expression of IRP2 just in protein levels rather than mRNA levels in the dopaminergic-like neuroblastoma cells (Figures 2A,B). 


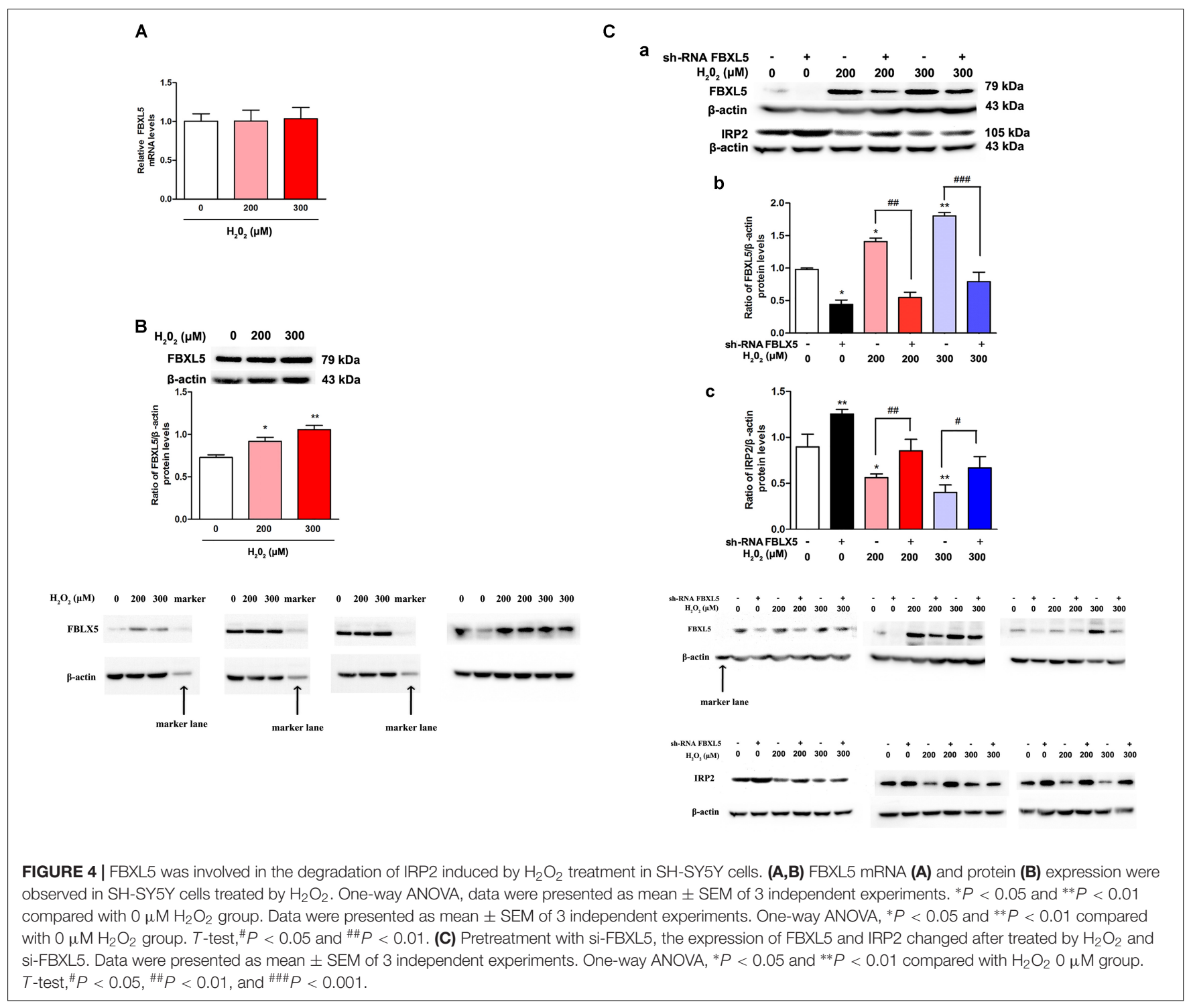

Correspondingly, TfR1 expression and cell iron uptake ability were reduced. As a key regulator of brain iron metabolism, IRP2 expression is accurately modulated by the microenvironment factors, including oxygen, iron, free radicals, and cytokines. Generally, neurodegenerative diseases have high oxidative stress level (Emerit et al., 2004; Kim et al., 2015). For example, oxidative stress is especially substantiated by the complex I mitochondrial dysfunction with increased ROS production that might induced by accumulated $\alpha$-synuclein and iron in the SN of PD patients (Jomova et al., 2010; Farina et al., 2013; Hwang, 2013). In our pervious study, we found that the expression of IRP2 mRNA levels was not affected by FAC at concentration of $100 \mu \mathrm{M}$ (Zhang et al., 2009). Moreover, sodium nitroprusside, a NO donor and an oxidative generator, could inhibit the IRP2 protein expression (Wei et al., 2017). The mechanism underlying oxidative stress-mediated down-regulation of IRP2 is complex. IRP2 mRNA transcription is regulated by HIF$\alpha$ of transcription factors that affected by oxygen and iron
(Kaelin and Ratcliffe, 2008). In post-transcriptional regulation, IRP2 was recognized by ubiquitin ligase and then degraded by the proteasome in kidney cell line (Salahudeen et al., 2009; Takahashi-Makise et al., 2009; Vashisht et al., 2009). However, the mechanisms of oxidative stress affect IRP2 expression in neurodegenerative diseases are largely unknown. We found that MG132 treatment could prevent the reduction of IRP2 that induced by $\mathrm{H}_{2} \mathrm{O}_{2}$ (Figure 3), suggesting that oxidative stress regulated IRP2 expression in dopaminergic-like neuroblastoma cells might be achieved through ubiquitination pathway.

There are two E3 ubiquitin ligases for IRP2, including FBXL5 and haem-oxidized IRP2 ubiquitin ligase 1 (HOIL1). HOIL-1 belongs to RING finger protein and recognizes IRP2 through a signal created by heme-mediated oxidative modification of the protein (Iwai et al., 2005). However, HOIL1 is independent and is not required for iron-dependent degradation of IRP2 (Zumbrennen et al., 2008). The selective iron- and oxygen-dependent degradation of IRP2 is mediated 
by the Skp1/Cul1/Fbox (SCF) E3 ubiquitin ligase complex containing FBXL5 (Salahudeen et al., 2009; Vashisht et al., 2009). Disruption of the FBXL5 expression are failed to sense the increased cellular iron availability, which results in constitutional accumulation of IRP2 and the disordered expression of its target genes (Salahudeen et al., 2009; Vashisht et al., 2009). In FBXL5 conditional deleted mice, hematopoietic stem cells are cellular iron overload and reduced in cell number (Muto et al., 2017). It is also found that $F B X L 5^{-/-}$mice die for overwhelming accumulation of oxidative stress during embryogenesis (Moroishi et al., 2011). Here, we found that FBXL5 increased and its targets IRP2 reduced when treated by $\mathrm{H}_{2} \mathrm{O}_{2}$ in SH-SY5Y cells. Thus, FBXL5 might be also referred to regulating IRP2 expression under oxidative stress condition in nerve system.

F box and leucine-rich repeat protein 5 contains a hemerythrin domain in the N-terminus that belongs to a family of iron- and oxygen-binding proteins, and contains the leucine-rich repeats in C-terminal region that binds to IRP2 (Salahudeen et al., 2009; Chollangi et al., 2012; Ruiz and Bruick, 2014). The N-terminal hemerythrin domain has iron and oxygen sensing properties for binding with Fe-O-Fe center. The Fe-O-Fe center is formed in iron replete and oxygenated cells. FBXL5 is stable when directly binds to iron in the hemerythrin domain, whereas unstable under iron-deficient conditions. With this iron-sensing ability, FBXL5 controls the abundance of IRP2 in an iron-dependent manner, and degrades IRP2 by the stabilized FBXL5 under iron-replete conditions. In addition to iron bioavailability, IRP stability and activity are regulated by oxygen. Acting as ROS sensors, the hemerythrin domain could also facilitate regulation by ROS that stabilizes FBXL5 and antagonizes the stabilization

\section{REFERENCES}

Butterfield, D. A., Drake, J., Pocernich, C., and Castegna, A. (2001). Evidence of oxidative damage in Alzheimer's disease brain: central role for amyloid beta-peptide. Trends Mol. Med. 7, 548-554. doi: 10.1016/S1471-4914(01)0 2173-6

Chollangi, S., Thompson, J. W., Ruiz, J. C., Gardner, K. H., and Bruick, R. K. (2012). Hemerythrin-like domain within F-box and leucine-rich repeat protein 5 (FBXL5) communicates cellular iron and oxygen availability by distinct mechanisms. J. Biol. Chem. 287, 23710-23717. doi: 10.1074/jbc.M112.360404

Dexter, D. T., Wells, F. R., Lees, A. J., Agid, F., Agid, Y., Jenner, P., et al. (1989). Increased nigral iron content and alterations in other metal ions occurring in brain in Parkinson's disease. J. Neurochem. 52, 1830-1836. doi: 10.1111/j.14714159.1989.tb07264.x

Dias, V., Junn, E., and Mouradian, M. M. (2013). The role of oxidative stress in Parkinson's disease. J. Parkinsons Dis. 3, 461-491. doi: 10.3233/JPD- 130230

Du, X., Xu, H., Shi, L., Jiang, Z., Song, N., Jiang, H., et al. (2016). Activation of ATP-sensitive potassium channels enhances DMT1-mediated iron uptake in SK-N-SH cells in vitro. Sci. Rep. 6:33674. doi: 10.1038/srep33674

Emerit, J., Edeas, M., and Bricaire, F. (2004). Neurodegenerative diseases and oxidative stress. Biomed. Pharmacother. 58, 39-46. doi: 10.1016/j.biopha.2003. 11.004

Farina, M., Avila, D. S., da Rocha, J. B., and Aschner, M. (2013). Metals, oxidative stress and neurodegeneration: a focus on iron, manganese and mercury. Neurochem. Int. 62, 575-594. doi: 10.1016/j.neuint.2012.12.006

Galy, B., Holter, S. M., Klopstock, T., Ferring, D., Becker, L., Kaden, S., et al. (2006). Iron homeostasis in the brain: complete iron regulatory protein 2 deficiency without symptomatic neurodegeneration in the mouse. Nat. Genet. 38, 967-969; discussion 969-970. doi: 10.1038/ng0906-967 of IRP2 (Ruiz and Bruick, 2014). In our present study, oxidative stress generators $\mathrm{H}_{2} \mathrm{O}_{2}$ could up-regulate FBXL5 expression (Figures 4A,B) and using si-FBXL5 could alleviate the reduction of IRP2 protein levels (Figure 4C), suggesting that the close relationship of FBXL5 and oxidative stress in regulation nerve system cellular iron metabolism.

In conclusion, we present novel evidence that the oxidative generators $\mathrm{H}_{2} \mathrm{O}_{2}$ induced an increase of FBXL5-mediated ubiquitination degradation in dopaminergic-like neuroblastoma cells. The results of this study implicate an important role of oxidative stress in regulating iron metabolism in nerve system.

\section{AUTHOR CONTRIBUTIONS}

HJ and QJ conceived the project and designed the study. QJ, JW, and XD performed the experiments, analyzed the data, and interpreted the results. QJ wrote the manuscript. HJ and YL reviewed and edited the manuscript. All authors have read and approved the final version of the manuscript.

\section{FUNDING}

This work was supported by the NSFC (31771110, 31500837, 31471114, and 81430024), National Key Research and Development Program of China (2016YFC1306500), the Key Research and Development Program of Shandong Province (2016GSF201053), Qingdao Municipal Science and Technology Project (16-2-2-nsh) and Taishan Scholars Construction Project.

Hentze, M. W., Muckenthaler, M. U., Galy, B., and Camaschella, C. (2010). Two to tango: regulation of mammalian iron metabolism. Cell 142, 24-38. doi: 10.1016/j.cell.2010.06.028

Hwang, O. (2013). Role of oxidative stress in Parkinson's disease. Exp. Neurobiol. 22, 11-17. doi: 10.5607/en.2013.22.1.11

Iwai, K., Ishikawa, H., and Kirisako, T. (2005). Identification, expression, and assay of an oxidation-specific ubiquitin ligase, HOIL-1. Methods Enzymol. 398, 256-271. doi: 10.1016/S0076-6879(05)98021-X

Iwai, K., Klausner, R. D., and Rouault, T. A. (1995). Requirements for ironregulated degradation of the RNA binding protein, iron regulatory protein 2 . EMBO J. 14, 5350-5357. doi: 10.1002/j.1460-2075.1995.tb00219.x

Jiang, H., Song, N., Xu, H., Zhang, S., Wang, J., and Xie, J. (2010). Up-regulation of divalent metal transporter 1 in 6-hydroxydopamine intoxication is IRE/IRP dependent. Cell Res. 20, 345-356. doi: 10.1038/cr.2010.20

Jomova, K., Vondrakova, D., Lawson, M., and Valko, M. (2010). Metals, oxidative stress and neurodegenerative disorders. Mol. Cell. Biochem. 345, 91-104. doi: 10.1007/s11010-010-0563-x

Kaelin, W. G. Jr., and Ratcliffe, P. J. (2008). Oxygen sensing by metazoans: the central role of the HIF hydroxylase pathway. Mol. Cell 30, 393-402. doi: 10.1016/j.molcel.2008.04.009

Kim, G. H., Kim, J. E., Rhie, S. J., and Yoon, S. (2015). The role of oxidative stress in neurodegenerative diseases. Exp. Neurobiol. 24, 325-340. doi: 10.5607/en.2015. 24.4.325

Kuhn, L. C. (2015). Iron regulatory proteins and their role in controlling iron metabolism. Metallomics 7, 232-243. doi: 10.1039/c4mt00164h

Meyron-Holtz, E. G., Ghosh, M. C., Iwai, K., LaVaute, T., Brazzolotto, X., Berger, U. V., et al. (2004). Genetic ablations of iron regulatory proteins 1 and 2 reveal why iron regulatory protein 2 dominates iron homeostasis. EMBO J. 23, 386-395. doi: 10.1038/sj.emboj.7600041 
Moroishi, T., Nishiyama, M., Takeda, Y., Iwai, K., and Nakayama, K. I. (2011). The FBXL5-IRP2 axis is integral to control of iron metabolism in vivo. Cell Metab. 14, 339-351. doi: 10.1016/j.cmet.2011.07.011

Muckenthaler, M. U., Galy, B., and Hentze, M. W. (2008). Systemic iron homeostasis and the iron-responsive element/iron-regulatory protein (IRE/IRP) regulatory network. Annu. Rev. Nutr. 28, 197-213. doi: 10.1146/annurev.nutr.28.061807.155521

Muto, Y., Nishiyama, M., Nita, A., Moroishi, T., and Nakayama, K. I. (2017). Essential role of FBXL5-mediated cellular iron homeostasis in maintenance of hematopoietic stem cells. Nat. Commun. 8:16114. doi: 10.1038/ncomms16114

Pong, K. (2003). Oxidative stress in neurodegenerative diseases: therapeutic implications for superoxide dismutase mimetics. Expert Opin. Biol. Ther. 3, 127-139. doi: 10.1517/14712598.3.1.127

Rouault, T. A. (2006). The role of iron regulatory proteins in mammalian iron homeostasis and disease. Nat. Chem. Biol. 2, 406-414. doi: 10.1038/ nchembio807

Ruiz, J. C., and Bruick, R. K. (2014). F-box and leucine-rich repeat protein 5 (FBXL5): sensing intracellular iron and oxygen. J. Inorg. Biochem. 133, 73-77. doi: 10.1016/j.jinorgbio.2014.01.015

Salahudeen, A. A., Thompson, J. W., Ruiz, J. C., Ma, H. W., Kinch, L. N., Li, Q., et al. (2009). An E3 ligase possessing an iron-responsive hemerythrin domain is a regulator of iron homeostasis. Science 326, 722-726. doi: 10.1126/science. 1176326

Smith, D. G., Cappai, R., and Barnham, K. J. (2007). The redox chemistry of the Alzheimer's disease amyloid beta peptide. Biochim. Biophys. Acta 1768, 1976-1990. doi: 10.1016/j.bbamem.2007.02.002

Smith, M. A., Wehr, K., Harris, P. L., Siedlak, S. L., Connor, J. R., and Perry, G. (1998). Abnormal localization of iron regulatory protein in Alzheimer's disease. Brain Res. 788, 232-236. doi: 10.1016/S0006-8993(98)00002-X

Sofic, E., Riederer, P., Heinsen, H., Beckmann, H., Reynolds, G. P., Hebenstreit, G., et al. (1988). Increased iron (III) and total iron content in post mortem substantia nigra of parkinsonian brain. J. Neural Transm. 74, 199-205. doi: 10.1007/BF01244786

Takahashi-Makise, N., Ward, D. M., and Kaplan, J. (2009). On the mechanism of iron sensing by IRP2: new players, new paradigms. Nat. Chem. Biol. 5, 874-875. doi: $10.1038 /$ nchembio.261 van Duijn, S., Bulk, M., van Duinen, S. G., Nabuurs, R. J. A., van Buchem, M. A., van der Weerd, L., et al. (2017). Cortical iron reflects severity of Alzheimer's disease. J. Alzheimers Dis. 60, 1533-1545. doi: 10.3233/JAD-161143

Vashisht, A. A., Zumbrennen, K. B., Huang, X., Powers, D. N., Durazo, A., Sun, D., et al. (2009). Control of iron homeostasis by an iron-regulated ubiquitin ligase. Science 326, 718-721. doi: 10.1126/science.1176333

Wang, J., Jiang, H., and Xie, J. X. (2004). Time dependent effects of 6-OHDA lesions on iron level and neuronal loss in rat nigrostriatal system. Neurochem. Res. 29, 2239-2243. doi: 10.1007/s11064-004-7031-5

Wei, J., Li, Y., Jiao, Q., Du, X. X., and Jiang, H. (2017). Influence of sodium nitroprusside on expressions of FBXL5 and IRP2 in SH-SY5Y cells. Sheng Li Xue Bao 69, 261-266.

Wilkinson, N., and Pantopoulos, K. (2014). The IRP/IRE system in vivo: insights from mouse models. Front. Pharmacol. 5:176. doi: 10.3389/fphar.2014.00176

You, L. H., Li, F., Wang, L., Zhao, S. E., Wang, S. M., Zhang, L. L., et al. (2015). Brain iron accumulation exacerbates the pathogenesis of MPTP-induced Parkinson's disease. Neuroscience 284, 234-246. doi: 10.1016/j.neuroscience.2014.09.071

Zhang, S., Wang, J., Song, N., Xie, J., and Jiang, H. (2009). Up-regulation of divalent metal transporter 1 is involved in 1-methyl-4-phenylpyridinium $(\mathrm{MPP}(+))$ induced apoptosis in MES23.5 cells. Neurobiol. Aging 30, 1466-1476. doi: 10. 1016/j.neurobiolaging.2007.11.025

Zumbrennen, K. B., Hanson, E. S., and Leibold, E. A. (2008). HOIL-1 is not required for iron-mediated IRP2 degradation in HEK293 cells. Biochim. Biophys. Acta 1783, 246-252. doi: 10.1016/j.bbamcr.2007.07.010

Conflict of Interest Statement: The authors declare that the research was conducted in the absence of any commercial or financial relationships that could be construed as a potential conflict of interest.

Copyright (c) 2019 Jiao, Du, Wei, Li and Jiang. This is an open-access article distributed under the terms of the Creative Commons Attribution License (CC BY). The use, distribution or reproduction in other forums is permitted, provided the original author(s) and the copyright owner(s) are credited and that the original publication in this journal is cited, in accordance with accepted academic practice. No use, distribution or reproduction is permitted which does not comply with these terms. 